\title{
ANALISIS KEBUTUHAN MODEL PEMBELAJARAN SEJARAH BERBASIS MULTIKULTURAL MASYARAKAT HUTAN TROPIS LEMBAB
}

\author{
Jamil, Muhamad Sopyan \\ Email: muhsopyan796@gmail.com
}

\begin{abstract}
Abstrak
Kondisi pembelajaran sejarah yang ada di SMAN Kota Samarinda masih memusatkan pada muatan materi, dan masih kurang mengintegrasikan nilai-nilai muatan lokal yang ada di masyarakat hutan tropis lembab. Sarana dan prasarana yang dimiliki oleh sekolah Menengah Atas Negeri Kota Samarinda seperti ketersediaan ruang kelas, laboratorium, perpustakaan, laboratorium sudah cukup baik dan memungkinkan untuk menggunakan model pembelajaran sejarah berbasis multikultural. Model pembelajaran sejarah berbasis multikultural senantiasa mempertimbangkan faktor potensial yang berbasis multikultur yang kemudian diintegrasikan dalam strategi pembelajaran berbasis multikultur.
\end{abstract}

Kata Kunci: Model Pembelajaran Sejarah, Berbasis Multikultura

\section{Pendahuluan}

Keberagaman suku, agama, etnis, dan bahasa menjadi kekayaan bangsa Indonesia. Keadaan ini menyebabkan Indonesia terkenal dengan negara multikultural, hal ini ditunjukkan oleh deferensiasi sosial dalam bentuk perbedaan etnis, sosial, budaya, agama, dan sebagainya (Supardi, 2014: 92).

Pemahaman terhadap keragaman oleh setiap masyarakat merupakan sebuah keharusan dan kewajiban sebagai negara multicultural. Apabila keadaan ini mampu dikelola dengan baik dan benar, maka akan mampu memberikan warna tersendiri dan harmoni yang memberikan daya tarik bagi bangsa lain. Walaupun demikian, Indonesia harus tetap antisipatif dan responsif terhadap fenomena heterogenitas kebudayaan dengan sikap arif dan bijak. Apabila tidak, maka akan menimbulkan dampak negatif berupa konflik yang melanda negeri ini, yang salah satunya disebabkan heterogenitas atau deferensiasi sosial dari masyarakat.(Sumantri, Bayu, \& Sugiartha, 2017: 192).

Tragedi kekerasan antar kelompok yang meledak secara sporadis di akhir tahun 1990-an di berbagi kawasan di Indonesia menunjukkan betapa rentannya rasa kebersamaan yang dibangun, betapa kentalnya prasangka antar kelompok dan betapa rendahnya nilai-nilai multikulturalisme. 
Pemahaman pendidikan multikultur hendaknya diberikan sejak dini sehingga dikemudian hari masyarakat akan mengerti terkait pentingnya menjaga keharmonisan dalam kehidupan masyarakat yang multikultur. Seperti yang dijelaskan Ainul Yakin (2006), bahwa pendidikan multikultural sangat penting diberikan kepada anak sejak dini di sekolah (Hanum, H \& Siska, 2009: 2).

Pendidikan multikultural yang dimaksudkan adalah suatu proses penanaman cara hidup menghormati, tulus, dan toleran terhadap keanekaragaman budaya yang hidup di tengah-tengah masyarakat plural. Dengan pendidikan multikultural, diharapkan adanya kekenyalan dan kelenturan mental bangsa menghadapi benturan konflik sosial, sehingga persatuan bangsa tidak mudah patah dan retak. Dari berbagai pendapat di atas dapat disimpulkan bahwa pendidikan multikultural merupakan ide, cita-cita, kesamaan pandangan, dan strategi menanamkan kesadaran multikultural melalui pendidikan (Supardi, 20142: 9).

Selain itu, penerapan pendidikan multikultural juga hendaknya dititikberatkan pada pemahaman dan penghargaan terhadap budayanya sendiri dan budaya orang lain (Misbahudholam, 2016). Beberapa sejarawan dan pengamat sosial berpendapat bahwa nasionalisme yang menyangkut integrasi bangsa perlu "direvitalisasi" (Supardan \& Ahamad, 1965). Untuk mewujudkan itu semua diperlukan suatu pendekatan multikultural (multicultural approach) diangkat dari munculnya gagasan perlunya pendidikan multi kultural (multicultural education) bagi kehidupan manusia dan keragaman bangsa di dunia (Atok, 2010: 21).

Pendekatan pendidikan multikultural ini muncul kepermukaan sebagai solusi alternative di era globalisasi saat ini dalam dunia pendidikan. Pendidikan sebagai teransformasi ilmu, pengetahuan dan budaya harusnya senantiasa mengedepankan wawasan multicultural. Hal ini berkaitan dengan ada kecenderungan pendidikan nasional masih bersifat keseragaman atau bisa dikatakan monokultur.

Wajah monokultural di dunia pendidikan masih kental sekali di berbagai dimensi, diantaranya adalah kurikulum, materi pelajaran, hingga metode pembelajaran yang disampaikan oleh guru selama proses belajar mengajar berlangsung Mahfud, (2011; 6). Namun dalam menyikapi multikulturalisme menurut Tilaar haruslah hati-hati, sebab multikulturaslisme dapat berkembang negatif ke arah hiper-multikulturalisme, dan chauvinisme seperti menganggap budaya sendiri yang paling baik, pertentangan antara budaya barat dengan sisa barat, upaya mencari-cari nilai-nilai asli atau "indegenous culture" seperti misalnya penguasa orde baru yang 
banyak menggunakan bahasa Kawi dalam memberikan nama-nama gedung yang sulit dimengerti oleh orang biasa. Hiper- multikulturaslisme yang lain adalah munculnya anggapan bahwa hanya penduduk asli yang dapat berbicara mengenai budayanya sendiri (Fauzan, Gamparan, \& Tengah, 2015).

Berdasarkan uraian di atas, maka tulisan ini berusaha untuk menilik lebih dalam terhadap kebutuhan model pembelajaran sejarah berbasis multikultural masyarakat hutan tropis lembab.

Berdasarkan latar belakang di atas maka rumusan masalah dalam tulisan ini sebagai berikut:

1. Bagaimana Kondisi Lingkungan Pembelajaran Sejarah berbasis multikultural di Kota Samarinda?

2. Bagaimana Model Pembelajaran Sejarah Berbasis Multikultural Masyarakat Hutan Tropis Lembabdi Kota Samarinda?

\section{Metodologi}

\section{Model Pembelajaran Sejarah}

Model pembelajaran pada dasarnya merupakan bentuk pembelajaran yang tergambar sejak awal sampai akhir dan disajikan secara khas oleh guru, dengan kata lain, model pembelajaran merupakan bungkus atau bingkai dari penerapan suatu pendekatan (Ahmad,.2011). Selain itu, model pembelajaran adalah kerangka konseptual yang melukiskan prosedur yang sistematik dan mengorganisasikan pengalaman belajar untuk mencapai tujuan belajar tertentu dan berfungsi sebagai pedoman para perancang pembelajaran dan para pengajar dalam merencanakan dan melakukan aktivitas pembelajaran (M. Ibrahim, 2007).Dengan demikian, model pembelajaran merupakan suatu pola interaksi siswa dengan guru di dalamkelas yang menyangkut pendekatan, strategi, metode, teknik pembelajaran yang diterapkan dalam pelaksanaan kegiatan belajar mengajar di kelas.

\section{a) Pembelajaran Sejarah}

Secara harpiah, pembelajaran sejarah terdiri dari dua kata, yaitu pembelajaran dan sejarah. Menurut Majid (2013: 4), istilah pembelajaran bermakna sebagai upaya untuk membelajarkan seseorang atau kelompok orang melalui berbagai upaya (effor) dan berbagai strategi, metode dan pendekatan kea rah pencapaian tujuan yang direncanakan. Adapun sejarah menurut Kochhar (2008: 3-5), pada hakikatnya sejarah adalah sebuah ilmu yang 
membahas tentang manusia dalam lingkup ruang dan waktu yang merupakan dialog antara peristiwa masa lampau dan perkembangan masa depan dengan menjelaskan masa kini.

Sasaran dalam pembelajaran sejarah adalah sesuatu yang ingin dicapai dengan dilaksanakannya pembelajaran tersebut. Menurut Porda (2009: 18), menjelaskan bahwa pembelajaran sejarah memiliki peran mengaktualisasikan dua unsur, yaitu unsur pembelajaran dan unsur pendidikan. Unsur pembelajaran yang diaktualisasikan adalah unsur pembelajaran dan intelektual, sdangkan unsur pendidikan yang diaktualisasikan adalah pembelajaran dan pendidikan moral bangsa yang demokratis dan bertanggung jawab keopada masa depan.

\section{Model Pendidikan Multikultural Berbasis Nilai Kearifan Lokal}

Implementasi Pendidikan multicultural di sekolah berbentuk pembelajaran multicultural. Oleh karena itu, perlu diperjelas dan diperjelas dan dipertegas tentang model pembelajaran multikultural dan juga pengembangan materi pembelajaran yang dapat diterapkan di sekolah.

Model-model pendidikan multikultural yang pernah ada dan sedang dikembangkan oleh negara-negara maju, dikenal lima pendekatan, yaitu: pertama, pendidikan mengenai perbedaanperbedaan kebudayaan atau multikulturalisme. Kedua, pendidikan mengenai perbedaanperbedaan kebudayaan atau pemahaman kebudayaan. Ketiga, pendidikan bagi pluralisme kebudayaan. Keempat, pendidikan dwi-budaya. Kelima, pendidikan multikultural sebagai pengalaman moral manusia.

James Banks (R. Ibrahim, 2013) menjelaskan bahwa pendidikan multikultural memiliki lima dimensi yang saling berkaitan dan dapat membantu guru dalam mengimplementasikan beberapa program yang mampu merespon terhadap perbedaan pelajar (siswa), yaitu: (1) Dimensi integrasi isi/materi (content integration). (2) Dimensi konstruksi pengetahuan (knowledge construction). (3) Dimensi pengurangan prasangka (prejudice ruduction). (4) Dimensi pendidikan yang sama/adil (equitable pedagogy). (5) Dimensi pemberdayaan budaya sekolah dan struktur sosial (empowering school culture and social structure).

\section{Nilai Kearifan Lokal}

Tujuan Pendidikan Multikulturalisme adalah untuk membentuk manusia yang berbudaya dalam menciptakan masyarakat yang berbudaya. Untuk mewujudkan pendidikan multikultur yang berbasis nilai lokal dalam pembelajaran khususnya pembelajaran sejarah diperlukan internalisasi nilai lokal beberapa tahapan, (Prasetiyo, 2016) yaitu: a) Transformasi nilai kearifan lokal masyarakat melalui keteladanan guru; b) Transaksi nilai kearifan lokal melalui penggunaan 
metode pembelajaran bahan ajar dan evaluasi pembelajaran yang sesuai. Metode pembelajaran yang digunakan adalah demokratis; c) Transinternalisasi Nilai.

Lebih lanjut, proses komunikasi kepribadian yang dilakukan dengan melihat secara langsung kepribadian guru dan mendengar nasehat berupa kebaikan nilai-nilai dan keburukan jika tidak/ kurang memiliki nilai-nilai tersebut munculah kesadaran dalam diri siswa tentang kebaikan nilai-nilai tersebut. Selanjutnya dari kesadaran diri yang terbentuk pada siswa munculah upaya untuk menginternalisasi nilai-nilai tersebut ke dalam diri mereka untuk menjadi bagian dalam diri mereka yang akhirnya diaktualisasikan dalam kehidupan sehari-hari mereka.

Jenis penelitian yang akan dilaksanakan adalah penelitian Kualitatif. Penelitian ini dilaksanakan di Sekolah Menegah AtasNegeri Samarinda. Teknik Pengumpulan data yang digunakan dalam penelitian ini yaitu observasi, wawancara dan dokumentasi.

Sumber data yang digunakan dalam penelitian ini adalah sumber data primer dan sumber data sekunder. Adapun teknik analisis data yang digunakan dalam penelitian ini adalah teknik Model Analisis Interaktif (Interaktive Analysis Models) yaitu pengumpulan data (data colection), reduksi data (data reduction), penyajian data (data display), dan penarikan kesimpulan (data verification).

\section{Hasil Penelitian dan Pembahasan}

\section{Kondisi Lingkungan Pembelajaran sejarah Berbasis Multikultural di Kota Samarinda}

Pembelajaran akan berjalan dengan baik apabila didukung oleh berbagai sarana fasilitas penunjang dalam suatu pembelajaran Sekolah Menengah Atas Negeri Kota Samarinda. Sarana yang dimaksud adalah kelengkapan ruang belajar, ruang praktik atau laboratorium yang dimiliki oleh sekolah seperti laboratorium IPA, Laboratorium Bahasa, dan Laboratorium Komputer.

1) Rombel, Guru dan Siswa

Rombongan Belajar yang ada di SMA Kota Samarinda variatif dikarenakan situasi dan kondisi masing-masing sekolah. Secara keseluruhan bahwa siswa yang ada di semua sekolah SMA Negeri yang ada di Samarinda tergolong banyak. Sekolah dengan jumlah siswa terbanyak adalah SMA Negeri 4 Samarinda dengan 1958 siswa, SMAN 1 Samarinda dengan 1630 siswa, SMAN 3 Samarinda dengan 1536 siswa, SMAN 2 Samarinda dengan 1322 siswa, dan SMAN 10 Samarinda 1471. Sedangkan untuk jumlah pendidik terbanyak adalah di SMAN 1 Samarinda dengan 38 guru, SMAN 10 dengan 36 guru, SMAN 4 Samarinda 34 guru. 


\section{2) Laboratorium}

Laboratorium yang ada di SMA Negeri Kota Samarinda bisa dikatakan cukup relevan dan refresentatif, dikarenakan secara keseluruhan semua sekolah mempunyai Laboratorium yang dilengkapi berbagai peralatan, sarana dan prasarana untuk penunjang berbagai kegiatan praktikum terutama praktik komputer. Jumlah laboratorium terbanyak adalah SMA 1 dengan 8 Laboratorium, SMAN 2 dengan 7 Laboratorium, diikuti SMAN 10 dengan 6 Laboratorium, SMAN 5 DAN 6 dengan 5 Laboratorium.

3) Perpustakaan

Untuk menciptakan pembelajaran yang optimal dibutuhkan sumber referensi yang sesuai, sehingga sarana dan prasarana berupa perpustakaan mutlak diperlukan. Adanya perpustakaan ini diharapkan mampu membantu siswa dan lainnya dan membantu berbagai kegaiatan dalam penunjang proses pembelajaran sejarah terutama dalam kaitannya dengan penggunaan media pembelajaran. Perpustakaan yang dipunyai oleh sekolah SMAN yang ada di Kota Samarinda cukup lengkap, dikarenakan sebagain besar sekolah sudah memiliki perpustakaan.

Perpustakaan yang dimiliki oleh sman di Kota Samarinda semuanya terdiri dari 1 perpustakaan dan hanya SMAN 15 Samarinda saja yang memiliki 2 perpustakaan.

4) Akses Internet

Akses internet sangat dibutuhkan dalam proses pembelajaran, apalagi saat ini kemajuan ilmu pengetahuan dan teknologi dalam berbagai bidang kehidupan dan keilmuan menuntut lembaga pendidikan dasar sampai perguruan tinggi untuk beradaptasi terhadap kemajuan zaman ini. Oleh karena itu, beberapa sekolah yang ada di Kota Samarinda melengkapi sekolahnya dengan internet yang bisa diakses oleh tenaga pendidik, tenaga pendidikan dan siswa dalam menunjang proses pembelajaran baik di dalam maupun di luar kelas.

Berdasarkan data17 sekolah Menengah atas negeri yang ada di Samarinda terdapat 4 sekolah yang masih terakses internet, artinya pihak sekolah tidak menyediakan fasilitas internet yang bias digunakan oleh guru, karyawan dan siswa.

\section{Kebutuhan Model Pembelajaran Sejarah Berbasis Multikultural di SMA Negeri Kota Samarinda}


Ada beberapa hal yang perlu dijadikan perhatian dalam mengembangkan pembelajaran berbasis multikultural

a. Melakukan analisis faktor potensial bernuansa multikultural

Analisis faktor yang dipandang penting dijadikan pertimbangan dalam mengembangkan model pembelajaran berbasis multikultural, yang meliputi:

1). Tuntutan kompetensi mata pelajaran yang harus dibekalkan kepada peserta didik berupa pengetahuan (knowledge), keterampilan (skills), dan etika atau karakter (ethic atau disposition).

2). Tuntutan belajar dan pembelajaran, terutama terfokus membuat orang untuk belajar dan menjadikan kegiatan belajar adalah proses kehidupan;

3). Kompetensi guru dalam menerapkan pendekatan multikultural;

4). Analisis terhadap latar kondisi siswa.

5). Karakteristik materi pembelajaran yang bernuansa multikultural.

b. Menetapkan strategi pembelajaran berkadar multikultural

Pilihan strategi yang digunakan dalam mengembangkan pembelajaraan berbasis multikultural, antara lain: strategi kegiatan belajar bersama-sama (Cooperative Learning), yang dipadukan dengan strategi pencapaian konsep (Concept Attainment) dan strategi analisis nilai (Value Analysis); strategi analisis sosial (Social Investigation). Beberapa Pilhan strategi ini dilaksanakan secara simultan, dan harus tergambar dalam langkah-langkah model pembelajaran berbasis multikultural.

c. Menyusunan rancangan pembelajaran berbasis multikultural

Penyusunan rancangan pembelajaran sejarah yang bernuansa multikultural, dapat dilakukan melalui lima tahapan utama, yaitu: (1) analisis isi (content analysis); (2) analisis latar kultural (setting analysis); (3) pemetaan materi (maping contents); (4) pengorganisasian materi (contents organizing) pembelajaran; dan (5) menuangkan dalam format pembelajaran.

\section{Kondisi Lingkungan Pembelajaran di SMA Negeri Kota Samarinda}


Untuk menunjang pembelajaran yang efektif diperlukan suatu metode yang tapat dalam pembelajaran khususnya pembelajaran sejarah, karena tidak sesuainya metode pembelajaran menyebabkan suasana pembelajaran khusunya pembelajaran sejarah menjadi kurang menyenangkan, siswa kurang termotivasi untuk belajar dan akhirnya menyebakan hasil belajar siswa menjadi rendah. Untuk itu, pemilihan dan penggunaan metode dan media pembelajaran yang sesuai dengan mata pelajaran sejarah dan dukungan sarana dan prasarana mutlak diperlukan.

\section{Kebutuhan Model Pembelajaran Sejarah Berbasis Multikultur di SMA Negeri Kota Samarinda}

Beberapa hal yang perlu dijadikan perhatian dalam mengembangkan pembelajaran berbasis multikultural

Analisis faktor yang dipandang penting dijadikan pertimbangan dalam mengembangkan model pembelajaran berbasis multikultural, yang yang meliputi: Tuntutan kompetensi mata pelajaran yang harus dibekalkan kepada peserta didik berupa pengetahuan (knowledge), keterampilan (skills), dan etika atau karakter (ethic atau disposition). Tuntutan belajar dan pembelajaran, Kompetensi guru dalam menerapkan pendekatan multicultural, Analisis terhadap latar kondisi siswa. Dan Karakteristik materi pembelajaran yang bernuansa multikultural.

Tujuan pendidikan multikulturalisme adalah untuk membentuk manusia yang berbudaya dalam menciptakan masyarakat yang berbudaya. Untuk mewujudkan pendidikan multikultur yang berbasis nilai lokal dalam pembelajaran khususnya pembelajaran sejarah diperlukan internalisasi nilai local (Prasetiyo, 2016) yaitu :

a) Transformasi nilai kearifan lokal masyarakat melalui keteladanan guru;

b) Transaksi nilai kearifan lokal melalui penggunaan metode pembelajaran bahan ajar dan evaluasi pembelajaran yang sesuai.

c) Selain itu diperlukan bahan ajar yang memadai dari sisi materinya. Materinya mengajarkan nilai-nilai luhur kemanusiaan, nilai-nilai bangsa, nilai-nilai kearifan local yang ada dalam masyarakat.

d) Transinternalisasi Nilai

Tahap terakhir dari proses internalisasi nilai-nilai yaitu tahap transinternalisasi. Tahap ini tidak hanya dilakukan dengan komunikasi verbal tetapi juga dengan sikap mental dan kepribadian.

694 | Seminar Nasional Sejarah ke 4 Jurusan Pendidikan Sejarah Universitas Negeri Padang 


\section{Simpulan}

Sarana dan prasarana yang dimiliki oleh sekolah Menengah Atas Negeri Kota Samarinda seperti ketersediaan ruang kelas, laboratorium, perpustakaan, laboratorium khususnya Laboratorium Komputer sudah cukup baik dan memungkinkan untuk menggunakan model pembelajaran sejarah berbasis multikultural khususnya mata pelajaran sejarah walaupun ada beberapa sekolah yang masih belum lengkap sarana dan prasarana.

Model pembelajaran sejarah berbasis multikulturalisme senantiasa mempertimbangkan faktor potensial yang berbasis multikultur yang kemudian diintegrasikan dalam strategi pembelajaran berbasis multikultur.

\section{DAFTAR PUSTAKA}

Ahmad, L.H. dkk. 2011. Strategi Pembelajaran Berorientasi KTSP. Jakarta: Prestasi Pelajar

Atok, A. R. Al. (2010). Dengan Pendekatan Multikultural Dalam Pendidikan Kewarganegaraan Di Perguruan Tinggi, 20, 20-30.

Fauzan, R., Gamparan, P. N., \& Tengah, K. (2015). Membangun nilai multikultural siswa melalui kajian sejarah perjuangan wanita di tingkat lokal, 1(25).

Hanum, H \& Siska, R. (2009). Implementasi Model Pembelajaran Multikultur di Sekolah Dasar di Provinsi Daerah Istimewa Yogyakarta. Artikel Multikultural-Stranas, 2(model Pembelajaran Multikultur), 1-17.

Ibrahim, M. (2007). Pengertian Model Pembelajaran, (Model Pembelajaran), 13-14.

Ibrahim, R. (2013). Pendiddikan Multikultural : Pengertian, Prinsip , dan Relevansinya dengan Tujuan Pendidikan Islam, 7(1), 129-154.

Ma'arif, S. (2015). Integrasi Nilai-Nilai Multikultural Dalam Pemelajaran Pendidikan Agama Ilam di SMP Dharma Lestari Salatiga. UIN Sunan Kalijaga.

Misbahudholam, M. (2016). Implementasi Pendidikan Multikultural Melalui Pendekatan Nilai Luhur Budaya Dan Pancasila Untuk Membangun Karakter Mahasiswa Dalam Menghadapi Arus Globalisasi. JTP2 IPS, 1 No. 2(Pendidikan Multikultur), 89-101.

Prasetiyo, E. (2016). Internalisasi Nilai Karakter Dalam Pembelajaran IPS. Metapora, 2 No. 2, 91-104.

Siregar, R. H. (2015). Pendidikan Multikulturalisme; Mengikis Sikap Radikalisme, Rasisme, dan 695 | Seminar Nasional Sejarah ke 4 Jurusan Pendidikan Sejarah Universitas Negeri Padang 
Diskriminisme Oleh Robiah Hidayah Siregar. Jurnal Madania, 5 : 2, 152-176.

Sugiyono. 2005. Metode Penelitian Pendidikan. Bandung: CV. Alfabeta

Sukardi, T. (n.d.). Mencari format baru pendidikan berbasis multikultural di indonesia.

Sumantri, M., Bayu, G. W., \& Sugiartha, M. (2017). Analisis Kebutuhan dalam Pengembangan Model Pendidikan Multikultur Transsformatif dalam Pembelajaran PPKn dan IPS di Sekolah Dasar, 1(September 2004), 192-197.

Supardan, D., \& Ahamad, R. (1965). Multikultural Dan Perspektif Sejarah Lokal , Nasional , Dan Global, 96-107.

Supardi. (2014). Pendidikan Multikultur Dalam Pembelajaran Sejarah Lokal. Jurnal Pembangunan Dan Pendidikan: Fondasi Dan Aplikasi, 2 No. 1(Pendidikan Multikultur), 91-99.

Zilfa, R. (2008). ( Studi Komparasi Pemikiran H . A . R Tilaar dan Said Nursi ) Fakultas Tarbiyah Universitas Islam NegerI ( UIN ) Malang 